\title{
Estimating the drilling rate in Ahvaz oil field
}

\author{
Masoud Cheraghi Seifabad $\cdot$ Peyman Ehteshami
}

Received: 28 December 2012/ Accepted: 5 May 2013/Published online: 25 May 2013

(C) The Author(s) 2013. This article is published with open access at Springerlink.com

\begin{abstract}
Optimizing the drilling operations depends on an understanding of the interaction between the drilling equipment and the geological formations at any given site and a reasonable estimation of the rate of drilling, given the operational parameters used in drilling. Therefore, it is very important to develop a model for estimation of the drilling rate, using the ground and operational parameters of the drill. These models provide for accurate prediction of achievable rates, time for the well completion and drilling costs as well as optimization of such crucial parameters as weight on the bit and the rotary speed. This paper will address the parameters affecting oil well drilling and uses the information from 50 oil wells in Ahvaz oil field to offer empirical equations for estimation of the drilling rates in related geological formations.
\end{abstract}

Keywords Oil field · Drilling rate - Modeling ·

Rock formations

\section{Introduction}

Due to relatively high cost of drilling operations, it is essential to develop an accurate prediction of drill performance and drilling rate to estimate the time needed for completion of a well and the related costs. Previous studies show that a small portion of the total drilling time is spent on actual rock cutting in the wall by the bit, and the rest is the downtime components that include traversing the rods in and out of the well. Obviously one of the ways to improve

M. C. Seifabad $(\bowtie) \cdot$ P. Ehteshami

Department of Mining Engineering, Isfahan University of

Technology, 84156-83111 Isfahan, Iran

e-mail: cheraghi@cc.iut.ac.ir the operation is to increase the bit efficiency and decrease drill downtime. Increasing the drilling efficiency means increasing the drilling rate by optimizing the combination of weight on bit (WOB) and rotational speed for the given bit in a given rock formation as well as increasing the ratio of drilling to bit trip time. In other words, increased drilling speed and higher number of hours spent on drilling as opposed to travel time results in higher drilling rate per day. This requires a good knowledge of the parameters controlling the drilling operation and the life of the drill bit.

In-depth study of the various drilling systems and their performance in a given site or region is the building block for improving the drilling operations. Such a study requires good record-keeping and relies on accurate records of drilling operations to develop a database of various parameters that can affect the drilling rates. Analysis of field data allows an engineer to model the relationship between the drilling rates and the related parameters.

Therefore, application of models for prediction of the drilling rate is necessary for (1) prediction of the time needed for drilling a well with a given size and specifications in a known group of rock formations and (2) selection of the optimum WOB and rotational speed of bit to increase the drilling rate. In the past 40 years, the researchers have introduced various models to predict the drilling rate. This includes the work by Bourgoyne and Young $(1974,1999)$ Bourgoyne et al. 2003; Maurer (1962); Cunningham (1978); Walker et al. (1986); Warren (1987); and Kahraman (1999). A number of the models were developed based on laboratory testing and others by field observations. Since the different parameters affect the drilling rate and the role of each parameter is not specifically defined, the need for a suitable method with a good level of accuracy is felt in all the areas. For this reason, the present study examined first a model of the drilling rate prediction in Ahvaz oil field. In 
doing so, the available relationship with the possibility of these models was specified to optimize the oil well drilling operation for future in Iran. The study used the bit data of 50 oil wells for modeling. Depending on the data, the number of effective parameters on the drilling rate presents a model utilizing multiple regression analysis. Minitab was used to apply regression analysis. This made it possible to determine the model correctly according to its capabilities. By considering the diversity of the rocks, variable conditions of drilling with different formations and inadequate data from the physical and mechanical properties of rocks, the idea was to reduce the data to find accurate and extendable results. Therefore, it was decided to introduce the models based on the formations.

\section{Drilling rate prediction models}

A number of the effective parameters on the drilling rate are as follows: load on bit, rotation, depth, rock strength, bit condition, formation pressure, mud weight, mud type, bit diameter, and mud flow rate (Bourgoyne and Young 1974). In each of the present modes, depending on laboratory or operational conditions, only a number of the effective parameters on oil well drilling were employed. This could lead to minor mistakes which, however, seem unavoidable.

\section{Bourgoyne and Young's model}

This model was introduced in 1974 and could count as one of the best. Al-Betairi et al. (1988) suggestion for the drilling rate prediction in the Persian Gulf based as it is on Bourgoyne and Young's model was successful. Bourgoyne model is as follows:

$$
\begin{aligned}
& \ln R=a_{1}+\sum_{j=2}^{8} a_{j} x_{j} \\
& x_{2}=10000-D \\
& x_{3}=D^{0.69}\left(g_{\mathrm{p}}-9\right) \\
& x_{4}=D\left(g_{\mathrm{p}}-\rho_{\mathrm{c}}\right) \\
& X_{5}=\ln \left(\frac{\frac{w}{d}-\left(\frac{w}{d}\right)_{\mathrm{t}}}{4-\left(\frac{w}{d}\right)_{\mathrm{t}}}\right) \\
& x_{6}=\ln \left(\frac{N}{100}\right) \\
& x_{7}=-h \\
& x_{8}=\frac{\rho q}{35 \mathrm{o} \mu d_{\mathrm{n}}}
\end{aligned}
$$

$R=$ Drilling rate $\left(\mathrm{ft} \mathrm{h}^{-1}\right), D=$ well depth $(\mathrm{ft})$, $g_{\mathrm{p}}=$ pore pressure gradient $\left(\mathrm{lb} \mathrm{gal}^{-1}\right), \rho_{\mathrm{c}}=$ equivalent mud density $\left(\mathrm{lb} \mathrm{gal}{ }^{-1}\right), \frac{w}{d}=$ weight on bit $\left(1,000 \mathrm{lb} \mathrm{in}^{-1}\right)$, $\left(\frac{w}{d}\right)_{\mathrm{t}}=$ threshold bit weight per inch of bit diameter $\left(1,000 \mathrm{lb} \mathrm{in}^{-1}\right), \quad N=$ rotary speed $(\mathrm{rpm}), \quad \rho=\operatorname{mud}$ density (lb $\left.\mathrm{gal}^{-1}\right), q=$ flow rate $\left(\right.$ gal $\left.\min ^{-1}\right), \mu=$ the apparent viscosity at $10,000 \mathrm{~s}^{-1}(\mathrm{cp}), d_{\mathrm{n}}=$ bit nozzle diameter (in), $h=$ Fractional tooth height worn away

Using this model requires a definition of $a_{1}$ to $a_{8}$ coefficients depending on the area chosen and the related data. Consequently the model is useful for a specific area. Various models have also been introduced by other investigators in the field. However, it is commonplace that each model considers only some of the effective parameters and ignores others. Consequently, each model may be valid in one area but not in others. Therefore, the final decision is to introduce a variety of models in the Ahvaz oil field area.

\section{Geological conditions}

Ahvaz oil field is located in Ahvaz (southeast of Iran). The formations are drilled as follows:

Agha Jari formation This consists of brown to grey limy sandstones, red marls with veins of gypsum and red siltstone.

Gachsaran formation This consists of anhydrite, red marl, grey marl and little limestone.

Asmari formation This includes carbonate and sandy facies associated with a little shale.

Sarvak formation This contains cream to brown limestone and shale.

Data processing

The drilling rate prediction models are developed by both laboratory and field work. The laboratory models embody not only the physical and mechanical properties but also the accurate measurements as they cannot simulate the real conditions. Therefore, they are inefficient. But the empirical models are more dependable and efficient than laboratory models because they are made under real conditions. Generally the models are dependable and usable for a specific rock type formation. Thanks to the advantages of the empirical over the laboratory models, a decision was made to introduce a model for prediction of the drilling rate in the Ahvaz oil field area based on the empirical data.

Type of data

The data are illustrated in terms of bit characteristics: bit number, bit size, make, bit type, nozzle size, depth and deviation, weight on bit, rotation, pump pressure, mud flow rate, mud weight, mud viscosity, and bit condition. 
Table 1 Parameters affecting Agha Jari model

\begin{tabular}{lcc}
\hline Parameters affecting drilling rate & Minimum & Maximum \\
\hline Bit diameter (in) & 17.5 & \\
Bit rotation (rpm) & 100 & 220 \\
Weight on bit (1,000 lb) & 7.5 & 82.5 \\
Depth (m) & 130.5 & $1,741.5$ \\
Mud density (pcf) & 61 & 74 \\
Mud viscosity (s) & 28 & 41
\end{tabular}

$\mathrm{ROP}=e^{(4.04+0.00458 N+0.0147 W-0.00101 D-0.0248 \mathrm{MW}-0.0169 \mathrm{MV}-0.0375 T)}$

$\bar{R}_{\mathrm{P}}^{2}=85.7 \%$

Table 2 Parameters affecting Gachsaran model

\begin{tabular}{lcc}
\hline Parameters affecting drilling rate & Minimum & Maximum \\
\hline Bit diameter (in) & 17.5 & \\
Bit rotation (rpm) & 95 & 210 \\
Weight on bit (1,000 1b) & 35 & 70 \\
Depth (m) & $1,528.5$ & $2,075.5$ \\
Mud density (pcf) & 70 & 78 \\
Mud viscosity (s) & 33 & 45 \\
\hline
\end{tabular}

$\mathrm{ROP}=8.83+0.00805 N+0.0427 W-0.00162 D-0.0843 \mathrm{MV}$

$\bar{R}_{\mathrm{P}}^{2}=77.2 \%$

Table 3 Parameters affecting Asmari model

\begin{tabular}{lcc}
\hline Parameters affecting drilling rate & Minimum & Maximum \\
\hline Bit diameter (in) & 8.375 & 8.5 \\
Bit rotation (rpm) & 50 & 90 \\
Weight on bit (1,000 1b) & 20 & 40 \\
Depth (m) & 2,511 & $2,820.5$ \\
Mud density (pcf) & 65 & 81 \\
Mud viscosity (s) & 28 & 59 \\
\hline ROP $=N^{0.6} W^{0.25} e^{(0.58-0.00209 \text { FROM+0.00158 TO-0.0199MW-0.0124MV-0.0574T) }}$ \\
$\bar{R}_{\mathrm{P}}^{2}=73.3 \%$
\end{tabular}

The modeling procedure

A desirable model for the drilling rate prediction is one which can be employed in different areas. Therefore, the modeling is designed based on the formation characteristics. It should be reminded that different bits are not treated identically for a specific formation and that performance depends on the bit structure. Hence, it was decided to use relatively similar bits in the models, e.g., the bit data were selected with no big difference in their structure and International Association of Drilling Contractors (IADC). This was done to reduce the number of the models and facilitate their use. In addition, provided the effect of the type and number of different factors are noted, the reason for the cases selected will be clarified. Thus, if the bit
Table 4 Parameters affecting Sarvak model

\begin{tabular}{lcc}
\hline Parameters affecting drilling rate & Minimum & Maximum \\
\hline Bit diameter (in) & 5.875 & 6.125 \\
Bit rotation (rpm) & 45 & 80 \\
Weight on bit (1,000 lb) & 5 & 25 \\
Depth (m) & 3,404 & $4,139.5$ \\
Mud density (pcf) & 71 & 80 \\
Mud viscosity (s) & 32 & 58
\end{tabular}

$\mathrm{ROP}=N^{0.65} W^{0.25} e^{(-2.26-0.00212 \text { FROM }+0.00251 \mathrm{TO}-0.0463 \mathrm{MV}-0.0120 T)}$

$\bar{R}_{\mathrm{P}}^{2}=67.2 \%$

rotation or the load on the bit is zero, the drilling rate must also be zero; otherwise, the drilling operation will stop. Nevertheless, in the present study the effect of mud specific gravity, mud viscosity, depth, bit diameter, bit rotation, weight on bit completely depends on drilling operations. Therefore, these depend on the type and parameters of the drilling rate. For each formation the coefficient of adjusted determination was examined. Hypothetical regression tests were run and graphs were plotted to present the actual and predicted values using the model in different cases. This resulted in selecting the most useful model. The different models are as follows (for the procedure of regression analysis reference is made to Wittink's book, 1992):

$\mathrm{ROP}=A_{1}+A_{2} N+A_{3} W+A_{4} \mathrm{MW}+A_{5} \mathrm{MV}+A_{6} T+A_{7} D$

$$
\begin{aligned}
\ln \mathrm{ROP}= & A_{1}+A_{2} N+A_{3} W+A_{4} M W+A_{5} M V+A_{6} T \\
& +A_{7} D
\end{aligned}
$$

$\mathrm{ROP}=A_{1}+\mathrm{A}_{2} \ln N+A_{3} \ln W+A_{4} \ln \mathrm{MW}+A_{5} \ln \mathrm{MV}$

$$
+A_{6} \ln T+A_{7} \ln D
$$

$\ln \mathrm{ROP}=A_{1}+A_{2} \ln N+A_{3} \ln W+A_{4} \ln \mathrm{MW}+A_{5} \ln \mathrm{MV}$

$$
+A_{6} \ln T+A_{7} \ln D
$$

$\frac{\mathrm{ROP}}{N^{\alpha} W^{\beta}}=A_{1}+A_{2} \mathrm{MW}+A_{3} \mathrm{MV}+A_{4} T+A_{5} D$

$\ln \frac{\mathrm{ROP}}{N^{\alpha} W^{\beta}}=A_{1}+A_{2} \mathrm{MW}+A_{3} \mathrm{MV}+A_{4} T+A_{5} D$

$\frac{\mathrm{ROP}}{N^{\alpha} W^{\beta}}=A_{1}+A_{2} \operatorname{lnMW}+A_{3} \ln \mathrm{MV}+A_{4} \ln T+A_{5} D$

$\ln \frac{\mathrm{ROP}}{N^{\alpha} W^{\beta}}=A_{1}+A_{2} \ln \mathrm{MW}+A_{3} \ln \mathrm{MV}+A_{4} \ln \mathrm{T}+A_{5} \mathrm{D}$

$A_{\mathrm{j}}=$ The coefficients depend on the type of formation, $\mathrm{ROP}=$ drilling rate $\left(\mathrm{m} \mathrm{h}^{-1}\right), N=$ rotary speed $(\mathrm{rpm})$, $W=$ weight on bit (1,000 lbs), MW = mud weight (pcf), $\mathrm{MV}=$ mud viscosity $(\mathrm{s}), T=$ bit condition (new bit or old 


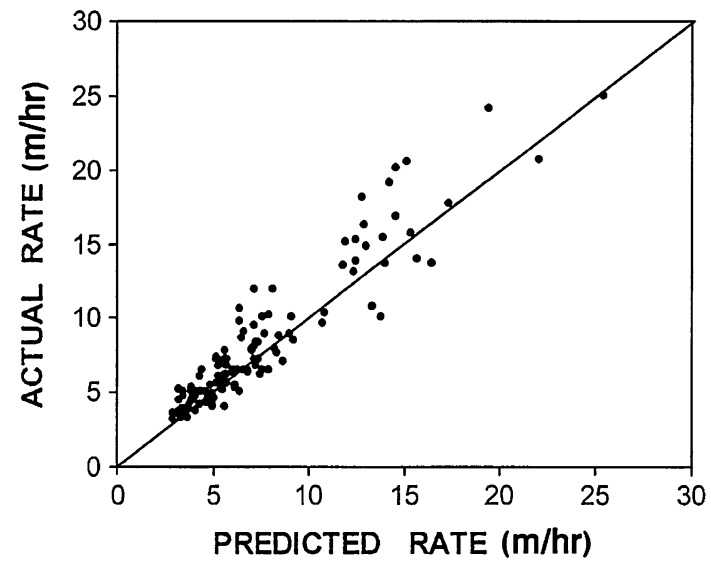

Fig. 1 Relation between actual and predicted drilling rate in Agha Jari model

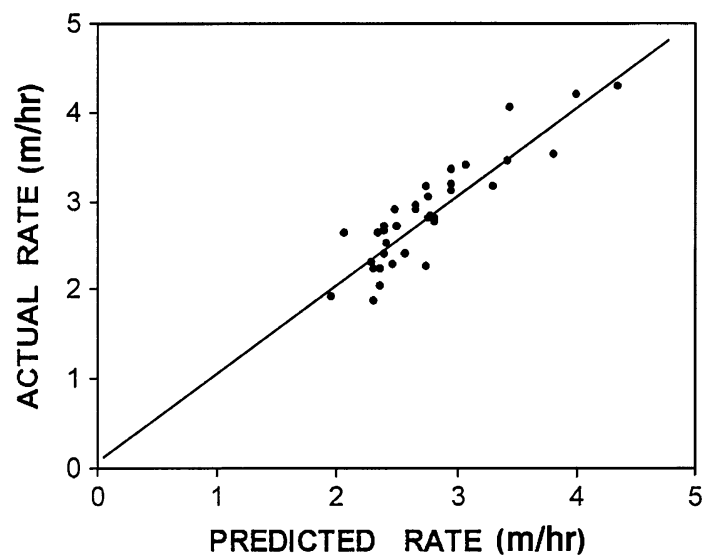

Fig. 2 Relation between actual and predicted drilling rate in Gachsaran model

one determined experimentally by drilling engineer), $D=$ depth $(\mathrm{m})$, From $=$ the depth when drilling is initiated, To $=$ depth on completion of drilling.

Drilling rate prediction models in Ahvaz oil field area

In this section, the drilling rate prediction model is introduced for four formations, Agha Jari, Gachsaran, Asmari and Sarvak. As the drilling rate conditions and parameters affecting them are similar for all the formations, the errors available for different models are relatively identical. This is significant in formations with a low drilling rate. It decreases the model accuracy. Compared with Agha Jari model, Gachsaran, Asmari and Sarvak have low accuracy due to the low drilling rate. In each of the models introduced, first the bit types are discussed and then Tables 1,2, 3 and 4 showing the range of effective parameters are introduced. Thus, the actual and predicted values of the

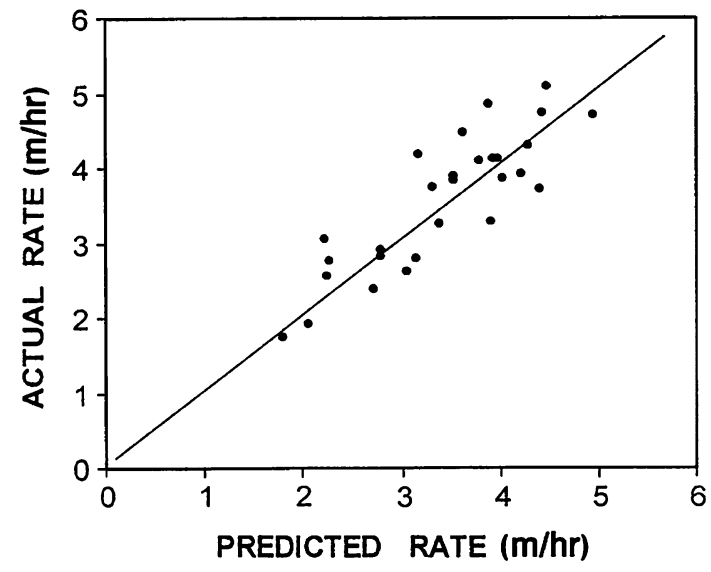

Fig. 3 Relation between actual and predicted drilling rate in Asmari model

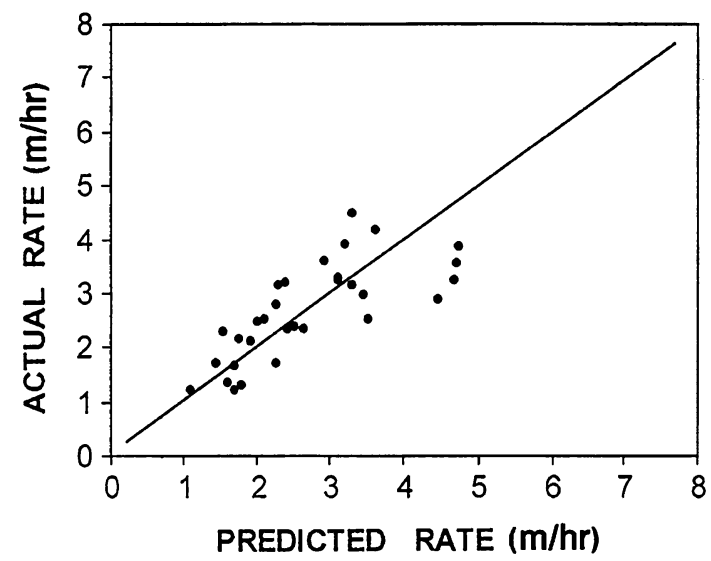

Fig. 4 Relation between actual and predicted drilling rate in Sarvak model

related models are represented in graphs (Figs. 1, 2, 3, 4) along with the coefficient of adjusted determination.

\section{Conclusion}

The present study was conducted on drilling operations in Ahvaz oil field and resulted in the following: (1) the sequence of layers in the manner and the depth available can predict the approximate boundaries of formations. Thus, the models introduced in Ahvaz oil field are both usable and generalizable. (2) The models introduced can predict the drilling rate and hence the time of the drilling operation and the expenses (i.e., the cost of drilling rig and other). Therefore, it is possible to use these models to choose the optimum weight on the bit and bit rotation.

Acknowledgments The authors would like to thank the drilling staff of National Iranian Oil Company (Southern Oil Fields) for their contribution and cooperation in this research. 
Open Access This article is distributed under the terms of the Creative Commons Attribution License which permits any use, distribution, and reproduction in any medium, provided the original author(s) and the source are credited.

\section{References}

Al-Betairi EA, Moussa MM, Al-Otaibi S (1988) Multiple regression approach to optimize drilling operations in the Arabian Gulf area. SPE Drill Eng 3(1):83-88

Bourgoyne AT, Young FS (1974) A multiple regression approach to optimal drilling and abnormal pressure detection. SPEJ 14(4): 371-384

Bourgoyne AT, Young FS (1999) A multiple regression approach to optimal drilling and abnormal pressure detection, society of petroleum engineers. SPE Reprints Series 49:27-40
Bourgoyne AT, Millheim KK, Chenevert ME, Young FS (2003) Applied drilling engineering. SPE, Richardson

Cunningham RA (1978) An empirical approach for relating drilling parameters. JPT 30(7):987-991

Kahraman S (1999) Rotary and percussive drilling prediction using regression analysis. Int J Rock Mech Min Sci 36(7):981-989

Maurer WC (1962) The "perfect-cleaning" theory of rotary drilling. JPT 14(11):1270-1274

Walker BH, Black AD, Klauber WP, Little T, Khodaverdian M (1986) Roller-bit penetration rate response as a function of rock properties and well depth, SPE 15620

Warren TM (1987) Penetration rate performance of roller-cone bits. SPE Drill Eng 2(1):9-18

Wittink Dick R (1992) The application of regression analysis. Prentice Hall, USA 